\title{
Deviancy and Normative Training Processes in Experimental Groups of Delinquent and Nondelinquent Male Adolescents
}

\author{
Cécile Mathys $^{1 *}$, Luke W. Hyde ${ }^{2,3}$, Daniel S. Shaw ${ }^{2}$, and Michel Born ${ }^{1}$ \\ ${ }^{1}$ Department of Psychology of Delinquency, Université de Liège, Liège, Belgium \\ ${ }^{2}$ Department of Psychology, University of Pittsburgh, Pittsburgh, Pennsylvania \\ ${ }^{3}$ Department of Psychology, University of Michigan, Ann Arbor, Michigan
}

\begin{abstract}
The goal of this study was to identify the predictors and the moderators of group characteristics that influence deviancy and normative training processes in delinquent male adolescents. The authors experimentally tested the effects of group composition on deviant talk interaction processes among groups in which all members presented delinquent behaviors ("pure" delinquent group condition), those that included adolescents with no delinquent behaviors ("pure" normative group condition), and adolescents with both profiles ("mixed" group condition). Participants were 70 male adolescents aged $15-18(M=16.5 ; 56 \%$ Caucasian), with a random assignment to groups. Data were collected among three group sessions (T1, T2, T3), one session a week, using videotape. Two contents of interactions were also measured: antisocial and normative stories, counterbalanced across sessions. Results showed a significant group effect for antisocial talk and its reinforcement, with less antisocial talk within the mixed group condition in comparison to the pure delinquent group condition. The topic of interaction was also observed as a predictor of antisocial talk, with less normative interactions and more antisocial talk associated with antisocial topics. Finally, time moderated some relations between experimental groups and talk. We conclude with a discussion of the implications of this work for future research on deviancy training processes. Aggr. Behav. 39:30-44, 2013. @ 2012 Wiley Periodicals, Inc.
\end{abstract}

Keywords: deviancy training process; juvenile delinquent; mixed groups; moderators; multilevel analysis

\section{INTRODUCTION}

Originally, social influence was hypothesized to be an important component in the treatment process for delinquent youth (Atwood \& Osgood, 1987; Short \& Strodtbeck, 1965; Wheeler, 1961), and change was associated with improvements in delinquent attitudes, values and behaviors, and appeared to be a positive factor in the treatment process (Deutsch, 1949; Vorrath \& Brendtro, 1974). More recently though, iatrogenic effects such as increases in delinquent behavioral patterns and higher consumption of illicit substances have been observed in groups of adolescent delinquents treated in group-based intervention programs (Ang \& Hughes, 2001; Dishion, Capaldi, Spracklen, \& Li, 1995; Mahoney, Stattin, \& Lord, 2004), a phenomenon termed "deviant peer contagion" in the literature (Bayer, Pintoff, \& Pozen, 2004). However, despite the negative effects of deviant peer contagion, because of practical, ethical, and economics costs, interventions with delinquents or antisocial adolescents continue to be carried out in group settings for the most part (Dishion, Dodge, \& Lansford, 2008; Dodge, Dishion, \& Lansford, 2006). Thus, there continues to be a need for studies that examine mechanisms that might underlie deviant peer contagion process.

Iatrogenic effects of deviant peers have been demonstrated broadly at a macro level. For example, studies have shown that contact with a high density of delinquent youth in residential settings appears to lead to higher rates of recidivism than similar youth living in the community (Shapiro, Smith, Malone, \& Collaro, 2010). Intervention studies also have shown that adolescents in group treatment have higher ratings of behavior problems and tobacco use, and more

\footnotetext{
*Correspondence to: Cécile Mathys, Department of Psychology of Delinquency, Université de Liége, Boulevard du Rectorat, B33 4000 Liège, Belgium. E-mail: cecile.mathys@ulg.ac.be

Received 24 November 2011; Accepted 28 August 2012

Published online 24 October 2012 in Wiley Online Library (wileyonlinelibrary.com).

DOI: $10.1002 / \mathrm{ab} .21456$
} 
positive attitudes toward illicit drugs postintervention than those in nongroup interventions (Dishion, Poulin, \& Burraston, 2001). However, beyond studies demonstrating this iatrogenic effect at the broad level, little is known about the mechanisms underlying these observed effects. While individual (e.g., individual's past delinquency) or setting factors (e.g., group composition) are known to be connected to deviant peer contagion, the main effects of these variables are still unclear (Mager, Milich, Harris, \& Howard, 2005; Shapiro et al., 2010). Thus, studies that address how microlevel processes contribute to this macrolevel effect can help expand our understanding of deviant peer contagion process in a more nuanced way. The present study focuses on micro processes underlying deviant peer contagion with adolescents that differ on history of antisocial behavior. A primary goal of the study was to examine how group design (i.e., ratio of delinquents to nondelinquents, structuring of the interactions) was associated with deviant peer contagion through deviant talk, based on prior research establishing as the salience of language to the dynamics of peer contagion (Dishion \& Tipsord, 2011).

\section{Peer Contagion and Antisocial Behavior}

Affiliation with deviant peers appears to be one of the strongest correlates of juvenile delinquency in early to mid-adolescence (Fergusson, Wanner, Vitaro, Horwood, \& Swain-Campbell, 2003; Patterson, Dishion, \& Yoerger, 2000; Thornberry and Krohn, 1997; Vitaro, Brendgen, \& Tremblay, 2001), with effects peaking around age of 14 (Brown, 1990; Steinberg \& Monahan, 2007). In particular, the most common outcome of deviant peer influence is antisocial behavior, especially among boys (Erickson, Crosnoe, $\&$ Dornbusch, 2000). Researchers have posited that this correlation results, at least in part, from a "drift into deviance," in which adolescents increase their antisocial behavior due to affiliation with deviant peers (Dishion, McCord, \& Poulin, 1999; Dishion, Spracklen, Andrews, \& Patterson, 1996). Thus, deviant peer influence may be driven by the strong social reinforcement derived from the approval of deviant behavior by like-minded peers (Born, 2005).

The harmful effects of peers appear to emerge most often when adolescents with the same type of problems are grouped in the same place. For example, when deviant adolescents are grouped together, the individuals in the group demonstrate an increase in deviancy (Chassin et al., 2004; Simons-Morton, Lerner, \& Singer, 2005). This phenomenon, called "deviant peer contagion" (Bayer et al., 2004), may inhibit or annul the positive effects that have been achieved by interventions (Dishion et al., 1999).
Researchers have argued that peer contagion is the result of a deviancy training process (Dishion et al., 1996; Dishion et al., 1999; Weiss et al., 2005) and thus the increase in deviant behaviors is driven by positive and reinforcing responses from peers to deviant talk or deviant behavior.

Observational research has found that deviant peer contagion can be seen at schools (Boxer, Guerra, Huesmann, \& Morales, 2005; Cho, Halfors, \& Sanchez, 2005; Hanish, Martin, Fabes, Leonard, \& Herzog, 2005; Kellam, Ling, Merisca, Brown, \& Ialongo, 1998; Snyder et al., 2005; Warren, Schoppelrey, Moberg, \& McDonald, 2005), in residential settings (Lee \& Thompson, 2009; Leve \& Chamberlain, 2005; Shapiro et al., 2010) and in neighborhoods (Plybon $\&$ Kliewer, 2001). However, experimental designs are needed because they can provide an opportunity to identify factors associated with the mechanisms of deviant peer contagion, and more strongly draw causal inferences from findings relative to correlational studies (Weiss et al., 2005).

\section{Deviant Peer Contagion in Treatment Settings}

In efforts to treat delinquent youth, several researchers have suggested that young offenders or aggressive adolescents could benefit from an improved repertoire of problem-solving techniques and a less egocentric perspective on their social information processing of external stimuli (Fontaine, Burks, \& Dodge, 2002; Hubbard, Dodge, Cillessen, Coie, \& Schwartz, 2001). Theoretically, these issues could be addressed from interventions that focus on social skills (Hawkins, Jenson, Catalano, \& Wells, 1991; Nangle, Erdley, Carpenter, \& Newman, 2002) and from attention regulation programs (Eisenberg, Smith, Sadovsky, \& Spinrad, 2004; Ellis, Rothbart, $\&$ Posner, 2004). Such interventions could prevent or mitigate delinquent behavior and recent research supports the efficacy of these programs (Lipsey, Wilson, \& Cothern, 2000; McMahon \& Wells, 1998; Pearson, Lipton, Cleland, \& Yee, 2002). While the theoretical promise of these interventions has been exciting, for practical and monetary reasons, these interventions are usually carried out in groups and thus individuals in these interventions are at-risk for iatrogenic effects due to their grouping with deviant peers. Moreover, group interventions that may negatively affect youth are widespread: the process of deviant peer contagion appears in educational, treatment, and correctional settings (Dishion et al., 1999; Dishion et al., 2008; Dishion \& Tipsord, 2011).

In residential treatments adolescents are often housed in rooms with peers and without adults (Dishion et al., 2008), and the ratio of reinforcement 
from peers compared to adults has been shown to be as high as 9 to 1 (Buehler, Patterson, \& Furniss, 1966). Thus, the inevitable daily contact with delinquent adolescents in residential settings has been linked to higher rates of recidivism than for similar youth remaining in a community setting who have the possibility of developing more relationships with nondelinquent peers (Lee \& Thompson, 2009; Leve \& Chamberlain, 2005; Shapiro et al., 2010). While these negative effects have been shown across several studies (Ang \& Hughes, 2001; Dishion et al., 1995; Dishion et al., 1996; Dishion, Eddy, Haas, Li, \& Spracklen, 1997; Dodge et al., 2006; Mahoney et al., 2004; Palinkas, Atkins, Miller, \& Ferreira, 1996; Patterson et al., 2000; Poulin, Dishion, \& Burraston, 2001; Valente et al., 2007), some studies have shown no relationship between the use of groupbased interventions with antisocial adolescents and increases in rates of antisocial behavior (Dennis et al., 2004; Handwerk, Field, \& Friman, 2000; Mager et al., 2005; Weiss et al., 2005). Moreover, a meta-analysis by Lipsey (2006) concluded that the literature did not reveal negative effects of group prevention programs relevant to antisocial behavior, but rather positive effects. This discrepancy in the literature begs the question of why some groups-based interventions show peer contagion effects and others do not. Hence, studies are needed that connect group processes that lead or do not lead to deviant talk and subsequent increases in antisocial behavior (Dishion et al., 2008). Moreover, given the reliance on group treatments, identifying factors that increase or mitigate deviant talk and subsequent peer contagion could inform the design of group interventions to minimize iatrogenic effects while maximizing treatment effects.

\section{Deviant Peer Contagion at the Microsocial Level}

To avoid or control deviant peer contagion inside group treatments, interventionists need to understand how these interactions may trigger positive or negative effects inside the group. To address this issue, some research is beginning to examine these interactions within group processes. Microsocial processes concern interpersonal interactions as a series of sequences and patterns that evolve over seconds or minutes (Dishion \& Tipsord, 2011). To illustrate the phenomenon of peer contagion, Dishion et al. (1996) analyzed the topics and response patterns of 206 adolescent male friend dyads during 25-min videotaped discussions and found that social reinforcement within the dyad was strongly associated with the conversation topic (i.e., deviant vs. normative). Indeed, in nondelinquent youth dyads social reinforcement tended to follow normative discussions, while in delinquent dyads the reinforcement occurred more often for rule-breaking conversations. Thus, the topic of conversation itself and the type of youth having the conversation may have an influence on what type of talk is reinforced.

Deviant peer contagion is also likely to be connected to group level variables, such as the ratio of deviant to nondeviant group members, the time spent together, and the structure of group (Dishion et al., 2008; Dodge et al., 2006; Fontaine \& Vitaro, 2006). Accordingly, the more an adolescent spends time with deviant peers, the more s/he may be influenced in a negative way. Moreover, studies have shown that the more aggressive youths there are within a group, the more the norms in the group become deviant (Boivin, Dodge, \& Coie, 1995; Stormshak, Bierman, Bruschi, Dodge, \& Coie, 1999; Wright, Giammarino, \& Para, 1986). Additionally, the reinforcements to aggressive behaviors are stronger within these groups than reinforcements to prosocial behaviors (Jonkmann, Trautwein, $\&$ Lüdtke, 2009). However, the presence of nondeviant peers can protect against these effects (Dodge et al., 2006; Hudley, Graham, \& Taylor, 2007; Vitaro, Tremblay, Kerr, Pagani, \& Bukowski, 1997) and positive peers could initiate a normative training process instead of deviancy training process (Hudley et al., 2007; Mager et al., 2005).

While much of the research in this area has begun to deepen our knowledge of how microlevel variables such as group characteristics may influence the overall likelihood and effect of deviance training, many questions still remain (Mager et al., 2005). Indeed, conflicting findings without control groups composed of only nondeviant adolescents (Feldman, 1992; Hudley \& Graham, 1993; Mager et al., 2005; Tremblay, Masse, Vitaro, \& Dobkin, 1995) have led to difficulty in improving our understanding how group characteristics may influence the peer contagion process and identify moderators of peer influence (Brechwald \& Prinstein, 2011). Moreover, the need to look at these factors and more proximal mechanisms (i.e., deviant talk rather than later delinquent behavior) has led to a gap in our understanding of the micro mechanisms within this larger process. Thus, to address these questions, studies that combine antisocial and nonantisocial adolescents together and examine the deviant talk process with a focus on group level variables are needed (Mathys \& Born, 2009; Weiss et al., 2005).

To address this need, the current study examined the relationship between deviant talk and group setting characteristics in which youth were randomly 
assigned to groups. Groups met on several occasions and the sample was comprised of an ethnically diverse group of Belgian adolescents. Specifically, normative talk, antisocial talk, and reinforcement to antisocial and normative talk were examined within a new group culture in which groups of four adolescents could interact under several conditions. By varying the proportion of peers with a history of antisocial activity and the inclusion of an adult in these newly formed groups (as would be expected in treatment settings where an adult should be present), the study was able to address some interesting questions. "Are groups with more normative adolescents likely to have more normative talk? How do group characteristics impact the talk?" The content of interactions (antisocial vs. normative) and the effect of multiple sessions together as a group were expected to predict changes in deviant talk. These group variables (i.e., content of interactions and time) were also expected to moderate the relation between groups of adolescents and talk, such that we expected groups showing less deviant talk and more normative interactions to occur in groups with no or few delinquent adolescents. We also expected growth in deviant talk to be more pronounced in groups comprised with a higher percentage of delinquent vs. nondelinquent youth.

\section{METHOD}

\section{Overview of Design and Hypotheses}

This study used a random assignment group design to test the effects of group composition on deviant talk interaction processes within adolescents aged 1518 years who varied with respect to ethnicity, socioeconomic status, and prior delinquency. Delinquent adolescents were randomly assigned to either pure delinquent groups (i.e., groups with only delinquent adolescents) or mixed groups (i.e., groups with delinquent adolescents and normative adolescents, in a 2:2 ratio) and normative adolescents were randomly assigned to either pure normative groups (i.e., groups with only normative adolescents) or mixed groups. Data about how participants interacted verbally and nonverbally with one another during the discussions were gathered throughout the sessions using videotape. Data about participants' general psychosocial functioning were gathered in a session prior to group formation.

\section{Participants}

The sample is composed of 70 male adolescents age 15-18 ( $\mathrm{M}=16.5, \mathrm{SD}=.98)$ from the Frenchspeaking parts of Belgium. Fifty-six percent of the participants were Caucasian and the rest were of
African and Moroccan descent. Thirty-six of the participants were classified as delinquent adolescents and 34 were nondelinquent adolescents. Delinquent adolescents came from residential care facilities and were under the care of the juvenile court at time of the study. In Belgium, residential care facilities house highly delinquent youth who have a history of recidivism (with three or more types of offenses) with individuals with more moderate and transient delinquency leading to a heterogeneous setting. Youth were drawn from four residential care facilities in different parts of Belgium, with different levels of delinquency. Delinquent adolescents were not attending school during their placement in residential care but previously they attended vocational high school or had dropped out of school. Normative adolescents were drawn from three typical Belgian French schools: two regular high schools (18 youths) and one vocational high school (16 youths). The schools were selected on the basis heterogeneous student population, regarding socioeconomic status, ethnicity, and educational level so as to be matched with the delinquent sample.

Youth were randomly split into three different types of conditions: "pure delinquent" groups (24 total delinquent adolescents), "pure normative" groups (22 total nondelinquent adolescents), and "mixed" group (12 delinquent adolescents and 12 nondelinquent adolescents). Each condition was composed of six subgroups with three or four adolescents (with a ratio of 2:2 for the mixed groups) within each group leading to 18 subgroups at all.

\section{Procedure}

This study was not part of a larger study and the youth had not met before; they participated only for the individual session and the three collective sessions. The study was explained to groups of youths in schools and residential facilities during class by the first author (as research staff) and was advertized to them as being a study about observing interactions among groups of peers. Approximately one-fourth of adolescents volunteered to participate. Participants provided informed consent and were assured before the initial interview and the group sessions that answers would not be shared with personnel in the residential care facilities or schools or parents. Parents were informed about the study by an official letter to return if they did not want their adolescent to participate to the study. As an incentive and reimbursement for their time, adolescents received a movie ticket at the end of group sessions. This study was also approved by the IRB of the University of Liege.

Data collection was divided in two parts: one initial individual interview and later a series of group 
meetings. After consenting to participate, each adolescent met individually with a researcher for an interview in a room inside the school or residential care facility. During this meeting, standardized questionnaires were used to evaluate the individual characteristic of the youths and the group sessions were explained. A total of 100 male adolescents participated to this initial interview, however only 70 youths of this sample agreed to participate in the collective sessions. Reasons for attrition (17 youths from schools and 13 ones from residential facilities) were the schedule of the youths (i.e., some youths had activities during the group sessions), the level of self-reported delinquency for others (i.e., some "normative" youths from schools showed quite high levels of self-reported delinquency) or the age (i.e., some youth were older than 18 years). Following the initial interview and the composition of groups (matching with age, socioeconomic status, and schedule), groups met in a neutral room inside a school, a residential care facility or a neutral room in the research laboratory depending on the type of group (pure delinquent groups in the residential treatment facility, pure normative groups in the school, and mixed groups in a neutral location). The group portion included three separate group sessions, with one meeting a week (lasting approximately $20 \mathrm{~min}$ ) for 3 weeks with a researcher and four adolescents (sometimes only three adolescents if one group member was missing).

During the group sessions, a researcher presented adolescents with both normative and antisocial stories and asked them to discuss these stories (Granic $\&$ Dishion, 2003). The researcher stayed in the room with the youths but did not interact with them. This approach was chosen to make the group sessions more similar to intervention settings where an adult is likely to be present. Moreover, it also made the setting more similar to other settings where delinquent and nondelinquent youth are likely to interact, such as school and sports teams. Within each session, the youth were presented with one normative and one antisocial story counterbalanced across sessions and these stories became more antisocial and more normative over time. For example, during the first session, antisocial (stealing in a shop) and normative (conflicts with parents) stories were presented, the second session presented moderately more normative (negotiation for student job with a strict boss) and antisocial (dealing drugs) stories, and the last session finished with higher levels of antisocial (attacking someone) and normative (helping friends) content of stories. As an example, this was the antisocial story used for the first group session: Mike works in a grocer's. One evening, while everything is quiet in the shop, David, a boy that Mike knows a little, comes in and approaches the counter "Hi! I have only got 2 euro in my pocket, would you mind giving me some chewing gum, a pack of cigarettes, and a pack of beer? I know that it's more expensive than 2 euro but as you are alone tonight, nobody will ever know it! I'll be even with you yet!". These stories came from Le Blanc, Dionne, Proulx, Grégoire, and Trudeau Le Blanc (1998) and presented a social dilemma to stimulate the discussions (Dishion et al., 1995; Englund, Levy, Hyson, \& Sroufe, 2000; Granic \& Hollenstein, 2003; Nas, Brugman, \& Koops, 2005). Although these topics may be relatively benign compared to current movies and video games, we were concerned about introducing any themes that were extreme, based on research showing that youth tend to imitate actors' behavior (Larsen, Engels, Granic, \& Overbeek, 2009; Larsen, Engels, Souren, Granic, $\&$ Overbeek, 2010). Moreover, these topics had been studied in the past in this population and thus we were confident of their validity. To choose the specific three stories, we used data from another project in which 12 stories were previously read by 70 other male adolescents similar in age, cultural origins, type of schools (vocational and high schools), and socioeconomic status to the current sample. These participants rated the normative or antisocial nature of each story using a Likert scale of 1 (non antisocial) to 10 (very antisocial). Using these ratings, we chose the three most antisocial and the three most normative for the current study. $t$ tests confirmed that the two groups of stories differed significantly in terms of their normative vs. antisocial nature $(t(69)=16.37 P<.001)$.

Finally, some participants ran away from their placements (for the delinquent adolescents in pure delinquent groups) or were sick (for the normative adolescents in mixed groups) at the time of sessions. Thus, some groups had only three participants for some sessions. As most group sessions contained four participants and the participation rate of adolescents for each group was $79 \%$, we used maximum likelihood estimation within Hierarchical Linear Modeling (HLM) to accommodate the occasional missing data.

\section{Measures}

Socioeconomic status. Socioeconomic status was measured using a "make ends meet" variable reported by adolescents (Callan \& Nolan, 1991) with a Likert scale from to 1 (it's very hard financially at home) to 5 (it's very easy financially at home). To assess socioeconomic status, we chose this method because some delinquent adolescents did not know the profession of their parents (e.g., some have no contact with their father, some report their parents are unemployed but these parents have illegal or black-market jobs). 
Across the entire sample, $23 \%$ of adolescents had two unemployed parents, $34 \%$ had one parent that was employed, and $43 \%$ had two employed parents.

Self-reported delinquency. A scale assessing past delinquency developed by Born, Spitz, and Gavray (2000) was used and presented to the adolescents via interview. Participants responded to the 26item scale that asked about behaviors using a 4-point response scale: $0=$ never; $1=$ in past (latest months or years); $2=$ now (latest weeks like a new deviant behavior), 3 = in past and now. Sample items include "fighting with others," "stealing," "burning a house," "drinking alcohol," and "carrying a weapon," among others. Note that delinquent adolescents from residential care facilities had some free weekends and thus many reported some deviant behaviors even though they were in residential care. The scale demonstrated good internal consistency $(\alpha=.99)$.

Observational measures. All observational data were collected during group sessions. All sessions were filmed and recorded. After filming, the content of sessions, both verbal and nonverbal were transcribed and coded (Larson \& Brown, 2007; Young et al., 2008) by three coders, one graduate, and two blind undergraduate students (Englund et al., 2000; Nas et al., 2005) with the Topic Code from peer interaction task (Peterson, Piehler, \& Dishion, 2006). In this study, the nontalk periods were not coded and thus only talk and nonverbal behaviors were coded. Each sentence from a participant was considered a unit and coded into three categories, that is, antisocial, normative, or reinforcement (Dishion et al., 1996; Feldman, 1992; Piehler \& Dishion, 2007) and summed to generate an overall amount of each type of talk per individual. The interrater reliability coefficients were calculated for antisocial topics, normative topics, reinforcements to antisocial topics, and reinforcements to normative topics with Pearson correlation (Englund et al., 2000). The interrater reliability was acceptable across antisocial topics $(r=.95-.99)$, normative $(r=.92-.95)$, antisocial reinforcements $(r=.81-.97)$, and normative reinforcements $(r=.97)$.

Four scores were calculated by summing adolescents' interactions (Peterson et al., 2006): (1) Antisocial includes talk that is not appropriate to the setting or task. Some of the topics in this category are mutually exclusive with normative topics because they are by definition inappropriate in any setting. Examples of these topics are all illegal activities, which include using drugs and alcohol or doing physical harm to someone else. Other topics are not illegal but inappropriate to this particular setting. Examples of these topics are obscene gestures or songs and talking about or doing gross activities. (2) Normative includes talk that is appropriate to the setting and task. This includes normative behavior and on-task behavior. All talk referencing "positive" principles, values, and actions are also coded normative. Normative talk and attitudes also includes off-task behavior or behavior that does not specifically fall into normative. Examples of normative coding are "having friends is important," "dealing drugs is bad," and questions about the sessions. (3) Antisocial reinforcements and (4) normative reinforcements - the verbal and nonverbal reinforcements compose the reinforcement variable, either antisocial or normative, depending on the sentence said before by another youth, and are coded for any verbalized single-word utterance of agreement or understanding. The nonverbal reinforcements collected by video include statements such as yeah, uh-huh, oh, hmm, smile, or laugh.

\section{Analytic Plan}

Because the adolescents participated in groups, these data were nonindependent and thus could potentially lead to erroneous findings if only traditional statistical analyses were computed, in which the individual is treated as the unit of analysis. Multilevel analysis is a general term referring to statistical methods appropriate for the analysis of nested data sets comprising several types of unit of analysis (Kashy, Donnellan, Burt, \& McGue, 2008; Kenny, Bolger, \& Kashy, 2002; Snijders, 2003) and was designed to handle dependencies in data that violate multivariate analyses and traditional linear regression assumptions (Bereiter, 1963; Burr \& Nesselroade, 1990; Willet, 1990). According to Arnold (1992, p. 58), HLM "estimates linear equations that explain outcomes for members of groups as a function of the characteristics of the groups as well as the characteristics of the members." Hierarchical linear modeling (Raudenbush \& Bryk, 2002) was used to test for effects of group (pure delinquent, pure normative, and mixed) on each dependent variable: normative talk, antisocial talk, reinforcement to antisocial talk, and reinforcement to normative talk with three steps of analyses including fixed predictors that can influence the outcomes but do not change between measures, individuals, or groups. Indeed, in small group research, group size is small, so there may not be enough individuals within each group to estimate slopes and intercept separately for each group (Kenny et al., 2002). In regards to missing data, these HLM models can still be estimated even when the data set is not perfectly balanced (Singer \& Willett, 2003). Even if individuals vary in the number of time points to which they contributed data, or if the spacing of data points differs between study participants, analyses are still robust. 
36 Mathys et al.

TABLE I. Differences of Individual Variables between the Three Experimental Conditions

\begin{tabular}{lcccc}
\hline & $\begin{array}{c}\text { Pure delinquent } \\
\text { group }(N=24) \\
\text { M (SD) }\end{array}$ & $\begin{array}{l}\text { Pure normative } \\
\text { group }(N=22) \\
\text { M (SD) }\end{array}$ & $\begin{array}{c}\text { Mixed } \\
\text { group }(N=24) \\
\text { M (SD) }\end{array}$ & $F(2,67)$ \\
\hline Age & $16.90(1.11)$ & $16.37(.82)$ & $16.30(.93)$ & 2.74 \\
Self delinquency & $16.29(4.26)$ & $7.41(4.57)$ & $8.96(5.66)$ & 22.20 \\
\hline$P<.05 ; * P<.01$. & & & &
\end{tabular}

\section{RESULTS}

Before directly presenting multilevel results, univariate results are first discussed. The multilevel analyses assume normality and homogeneity of errors. Thus, an analysis of variance test for normality was used to check that the continuous variables came from the standard normal distribution: the ShapiroWilk statistic showed for all independent and dependent variables that the distribution was normally distributed and a Levene test confirmed homogeneity of variances.

\section{Preliminary Results}

Table I shows the differences between the participants in the pure delinquent, pure normative, and mixed conditions on age and self-reported delinquency. As expected the groups differed with respect to self-reported delinquency score $(F(2,67)=22.20$, $P<.01)$ : adolescents in the pure delinquent condition were the most delinquent, following by adolescents from the mixed condition and adolescents in the pure normative condition were the least delinquent. Beyond being higher on self-reported delinquency, the groups appeared to differ with respect to the severity of their behaviors: the typical behaviors committed by nondelinquent adolescents were drinking alcohol, smoking, marijuana, and stealing during their childhood; while delinquent adolescents committed more serious behaviors such as hurting peers, stealing money, and acts of serious violence. After being randomized to group, the youth in each of the three conditions were not found to differ in terms of socioeconomic status $\left(\chi^{2}(2)=.33, P=.85\right)$ but age differed marginally between groups $(F(2,67)=2.74$, $P=.07)$ and was used as a control variable in the HLM models.

\section{Multilevel Analyses}

There were four steps in these multilevel analyses: (1) estimating the fully unconditional models, (2) estimating the across time model, (3) estimating the within-group models, and (3) estimating the betweengroup models or final model. The fully unconditional models were used to partition the total variance in the outcome variable across time and within- and between-group components, and to estimate the proportion of the total variance that between groups. Next, across time models were run to estimate regression coefficients in each type of measures used. At this level, regression equations for each measure predicted normative talk, antisocial talk, and their reinforcements. These intercepts were then used as the dependent variables in the within-group models to be simultaneously explained as a function of individual differences within groups. The same process was used for the between-group models when the unit of analysis was individuals and the independent variables were the group condition.

\section{Normative Talk Model}

First, normative talk was examined as an outcome (see Table II). In this model, the effect of the type of story significantly predicted normative talk: the more the story was antisocial, the less the group talk was normative. There was no effect of time (number of meetings) on normative talk in the final model. Next, the effect of experimental groups (pure delinquent, pure normative, and mixed) on normative talk was tested. However and surprisingly, there were no significant differences between the three conditions. Finally, moderator effects were examined to determine if independent variables of level 1 (time and story) moderated any of the relations between experimental conditions and normative talk. None of the interactions terms reached significance $(P>.05)$, indicating that time and type of story did not moderate any of the associations between experimental conditions and normative talk.

\section{Reinforcements to Normative Talk Model}

Similarly, the effects of these predictor variables on reinforcement to normative talk were examined (Table III). Type of story significantly predicted reinforcements to normative talk: the more the story was antisocial, the less the group of adolescents used reinforcements to normative talk. On level 1, no effect of time on reinforcements to normative talk was found. There were no effects for time (number of sessions) on reinforcements to normative talk. 
TABLE II. Differences of Normative Talk between the Three Experimental Conditions

\begin{tabular}{|c|c|c|c|c|}
\hline Fixed effects & $\begin{array}{c}\text { Baseline model } \\
\text { Standardized estimate }(p)\end{array}$ & $\begin{array}{c}\text { Model } 1 \\
\text { Standardized estimate (p) }\end{array}$ & $\begin{array}{c}\text { Model } 2 \\
\text { Standardized estimate (p) }\end{array}$ & $\begin{array}{c}\text { Final model } \\
\text { Standardized estimate }(p)\end{array}$ \\
\hline Intercept & $18.29(.00)^{* * *}$ & $23.86(.00)^{* *}$ & $23.85(.00)^{* *}$ & $18.11(.00)^{* *}$ \\
\hline \multicolumn{5}{|l|}{ Level 1} \\
\hline Time2 & & $-3.90(.01)^{* *}$ & $-3.90(.01)^{* *}$ & $-2.09(.43)$ \\
\hline Time3 & & $-2.72(.09)$ & $-2.71(.08)$ & $-1.34(.63)$ \\
\hline Antisocial story & & $-6.93(.00)^{* *}$ & $-6.93(.00)^{* *}$ & $-6.90(.00)^{* * *}$ \\
\hline \multicolumn{5}{|l|}{ Level 2} \\
\hline Age & & & $.22(.90)$ & $1.03(.76)$ \\
\hline \multicolumn{5}{|l|}{ Level 3} \\
\hline Normative & & & & $9.25(.11)$ \\
\hline Mixed & & & & $8.25(.15)$ \\
\hline Time $2 *$ normative & & & & $.24(.95)$ \\
\hline Time $2 *$ mixed & & & & $-5.61(.14)$ \\
\hline Time 3 " normative & & & & $.10(.98)$ \\
\hline Time $3 *$ mixed & & & & $-4.24(.27)$ \\
\hline Antisocial story " normative & & & & $-3.49(.26)$ \\
\hline Antisocial story " mixed & & & & $3.28(.29)$ \\
\hline Random effects & Variance, $P$ value & Variance, $P$ value & Variance, $P$ value & Variance, $P$ value \\
\hline Level $1 \varepsilon_{i j k}$ & 172.72 & 154.28 & 154.29 & 150.20 \\
\hline Level $2 r_{0 j k}$ & $49.44(.00)^{* *}$ & $53.87(.00)^{* *}$ & $53.77(.00)^{* *}$ & $50.42(.00)^{* *}$ \\
\hline Level $3 u_{00 k}$ & $57.04(.00)^{* * *}$ & $57.49(.00)^{* *}$ & $57.56(.00)^{* *}$ & $46.42(.00)^{* *}$ \\
\hline
\end{tabular}

$* P<.05, * * P<.01$

At level 3, there were no significant differences between adolescents in the pure normative and pure delinquent conditions, but adolescents in the mixed groups demonstrated greater reinforcements to normative talk than those in the pure delinquent group. Finally, moderator analyses revealed that the number of collective meetings moderated the association between experimental conditions and reinforcements to normative talk. At time 2, adolescents from mixed condition demonstrated less reinforcement to normative talk than adolescents in the pure delinquent group. The opposite result was observed for adolescents from the pure normative condition; these youth used more reinforcements to normative talk at time 3 compared to adolescents in the pure delinquent group.

TABLE III. Differences of Reinforcements to Normative Talk between the Three Experimental Conditions

\begin{tabular}{|c|c|c|c|c|}
\hline Fixed effects & $\begin{array}{c}\text { Baseline model } \\
\text { Standardized estimate }(\mathrm{p})\end{array}$ & $\begin{array}{c}\text { Model 1 } \\
\text { Standardized estimate (p) }\end{array}$ & $\begin{array}{c}\text { Model } 2 \\
\text { Standardized estimate }(\mathrm{p})\end{array}$ & $\begin{array}{c}\text { Final model } \\
\text { Standardized estimate }(\mathrm{p})\end{array}$ \\
\hline Intercept & $8.05(.00)^{* * *}$ & $10.43(.00)^{* * *}$ & $10.43(.00)^{* * *}$ & $7.79(.00)^{* * *}$ \\
\hline \multicolumn{5}{|l|}{ Level 1} \\
\hline Time2 & & $-2.32(.01)^{* *}$ & $-2.32(.00) * *$ & $-.70(.57)$ \\
\hline Time3 & & $-.32(.67)$ & $-.32(.66)$ & $-1.40(.28)$ \\
\hline Antisocial story & & $-3.07(.00) * *$ & $-3.07(.00) * *$ & $-.3 .43(.00) * *$ \\
\hline \multicolumn{5}{|l|}{ Level 2} \\
\hline Age & & & $-.78(.94)$ & $.37(.84)$ \\
\hline \multicolumn{5}{|l|}{ Level 3} \\
\hline Normative & & & & $1.31(.68)$ \\
\hline Mixed & & & & $6.61(.04)^{*}$ \\
\hline Time $2 *$ normative & & & & $-.55(.75)$ \\
\hline Time $2 *$ mixed & & & & $-4.29(.02)^{*}$ \\
\hline Time $3 *$ normative & & & & $3.74(.04) *$ \\
\hline Time $3 *$ mixed & & & & $-.68(.70)$ \\
\hline Antisocial story " normative & & & & $.69(.64)$ \\
\hline Antisocial story " mixed & & & & $.38(.79)$ \\
\hline Random effect & Variance, $P$ value & Variance, $P$ value & Variance, $P$ value & Variance, $P$ value \\
\hline$\overline{\text { Level } 1 \varepsilon_{i j k}}$ & 38.18 & 34.03 & 34.03 & 32.71 \\
\hline Level $2 r_{0 j k}$ & $17.99(.00)^{* * *}$ & $18.69(.00)^{* *}$ & $18.69(.00) * *$ & $17.18(.00)^{* * *}$ \\
\hline Level $3 u_{00 k}$ & $21.71(.00) * *$ & $22.08(.00) * *$ & $22.06(.00) * *$ & $18.14(.00)^{* * *}$ \\
\hline
\end{tabular}

$* P<.05 . * P<.01$. 
38 Mathys et al.

TABLE IV. Differences of Antisocial Talk between the Three Experimental Conditions

\begin{tabular}{|c|c|c|c|c|}
\hline Fixed effects & $\begin{array}{c}\text { Baseline model } \\
\text { Standardized estimate }(\mathrm{p})\end{array}$ & $\begin{array}{c}\text { Model 1 } \\
\text { Standardized estimate }(\mathrm{p})\end{array}$ & $\begin{array}{c}\text { Model } 2 \\
\text { Standardized estimate }(\mathrm{p})\end{array}$ & $\begin{array}{c}\text { Final model } \\
\text { Standardized estimate }(\mathrm{p})\end{array}$ \\
\hline Intercept & $10.83(.00)^{* *}$ & $4.63(.02)^{*}$ & $4.60(.02) *$ & $9.75(.00) * *$ \\
\hline \multicolumn{5}{|l|}{ Level 1} \\
\hline Time2 & & $10.16(.00)^{* *}$ & $10.17(.00) * *$ & $8.88(.00)^{* *}$ \\
\hline Time3 & & $-1.81(.28)$ & $-1.76(.29)$ & $-6.37(.03)^{*}$ \\
\hline Antisocial story & & $6.92(.00)^{* * *}$ & $6.92(.00) * *$ & $7.70(.00) * *$ \\
\hline \multicolumn{5}{|l|}{ Level 2} \\
\hline Age & & & $1.07(.37)$ & $1.07(.62)$ \\
\hline \multicolumn{5}{|l|}{ Level 3} \\
\hline Normative & & & & $-5.13(.22)$ \\
\hline Mixed & & & & $-10.32(.02)^{*}$ \\
\hline Time 2 * normative & & & & $1.36(.73)$ \\
\hline Time $2 *$ mixed & & & & $2.53(.53)$ \\
\hline Time $3 *$ normative & & & & $4.71(.25)$ \\
\hline Time $3 *$ mixed & & & & $8.90(.03)^{*}$ \\
\hline Antisocial story " normative & & & & $-.01(.99)$ \\
\hline Antisocial story " mixed & & & & $-2.20(.50)$ \\
\hline Random effects & Variance, $P$ value & Variance, $P$ value & Variance, $P$ value & Variance, $P$ value \\
\hline Level $1 \varepsilon_{i j k}$ & 215.78 & 173.07 & 173.07 & 169.86 \\
\hline Level $2 r_{0 j k}$ & $.12(.50)$ & $2.29(.40)$ & $1.70(.40)$ & $.25(.50)$ \\
\hline Level $3 u_{00 k}$ & $25.55(.00) * *$ & $25.60(.00)^{* *}$ & $25.93(.00) * *$ & $16.53(.00) * *$ \\
\hline
\end{tabular}

*P<.05. *P<.01

\section{Antisocial Talk Model}

A similar model to above was run with antisocial talk as the outcome (see Table IV). At level 1, the effect of the type of story significantly predicted antisocial talk: the more the story was antisocial, the more the group talk was antisocial. In terms of the effect of number of meetings, there was as effect of time 2 and time 3 on antisocial talk: the peak of antisocial talk occurred at time 2 and decreased at time 3. At level 3, there were some significant differences between the three conditions: adolescents in the mixed condition spoke less about antisocial topics than delinquent adolescents from the pure delinquent condition. There were no significant differences between adolescents in the pure normative vs. pure delinquent conditions. Finally, moderator analyses indicated that time moderated the association between experimental conditions and antisocial talk: as observed in Fig. 1, time 3 showed more antisocial talk inside mixed groups than pure delinquent groups.

\section{Reinforcements to Antisocial Talk Model}

Table $\mathrm{V}$ presents the results of the model predicting reinforcements to antisocial talk. In level 1, the effect of the type of story significantly predicted reinforcements to antisocial talk: the more the story was antisocial, the more the group of adolescent reinforced antisocial talk. Time (number of meetings) was also a predictor with more reinforcements to an-

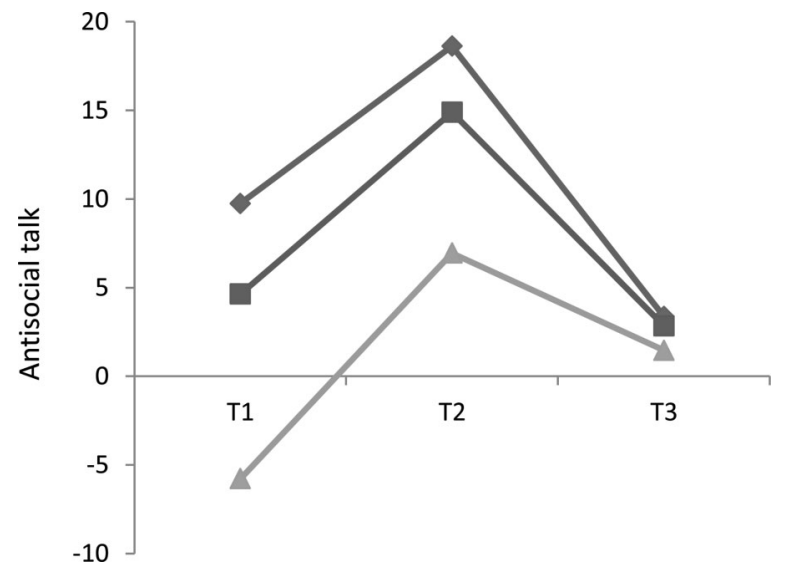

Fig. 1. Levels of antisocial talk over the three sessions between experimental groups. The first line from the top is for pure delinquent groups, the middle line represents pure normative groups, and the bottom line is for mixed groups.

tisocial talk in each experimental condition at time 2 . In level 3, there were some significant differences between the three conditions: adolescents in the mixed condition used less reinforcement to antisocial talk in comparison to adolescents from the pure delinquent condition. There were no significant differences between adolescents in the pure normative and pure delinquent conditions. Finally, the moderator analyses indicated that there was a trend for time moderating the association between experimental conditions and reinforcements to antisocial talk $(P=.06)$ : time 
TABLE V. Differences of Reinforcements to Antisocial Talk between the Three Experimental Conditions

\begin{tabular}{|c|c|c|c|c|}
\hline Fixed effects & $\begin{array}{c}\text { Baseline model } \\
\text { Standardized estimate (p) }\end{array}$ & $\begin{array}{c}\text { Model } 1 \\
\text { Standardized estimate (p) }\end{array}$ & $\begin{array}{c}\text { Model } 2 \\
\text { Standardized estimate (p) }\end{array}$ & $\begin{array}{c}\text { Final model } \\
\text { Standardized estimate }(p)\end{array}$ \\
\hline Intercept & $7.88(.00)^{* * *}$ & $2.53(.09)$ & $2.52(.09)$ & $5.40(.03)^{*}$ \\
\hline \multicolumn{5}{|l|}{ Level 1} \\
\hline Time2 & & $8.68(.00)^{* * *}$ & $8.68(.00)^{* * *}$ & $9.53(.00)^{* * *}$ \\
\hline Time3 & & $-.88(.50)$ & $-.84(.52)$ & $-3.78(.10)$ \\
\hline Antisocial story & & $5.56(.00)^{* *}$ & $5.56(.00)^{* * *}$ & $6.89(.00)^{* * *}$ \\
\hline \multicolumn{5}{|l|}{ Level 2} \\
\hline Age & & & $.75(.41)$ & $.69(.68)$ \\
\hline \multicolumn{5}{|l|}{ Level 3} \\
\hline Normative & & & & $-2.51(.44)$ \\
\hline Mixed & & & & $-6.14(.07)$ \\
\hline Time2 * normative & & & & $-1.13(.72)$ \\
\hline Time $2 *$ mixed & & & & $-1.46(.64)$ \\
\hline Time 3 * normative & & & & $2.66(.41)$ \\
\hline Time3 $*$ mixed & & & & $5.92(.06)$ \\
\hline Antisocial story " normative & & & & $-.71(.79)$ \\
\hline Antisocial story " mixed & & & & $-3.17(.22)$ \\
\hline Random effects & Variance, $P$ value & Variance, $P$ value & Variance, $P$ value & Variance, $P$ value \\
\hline Level $1 \varepsilon_{i j k}$ & 136.67 & 109.40 & 109.16 & 106.17 \\
\hline Level $2 r_{0 j k}$ & $.05(.50)$ & $.57(.40)$ & $.05(.50)$ & $.04(.50)$ \\
\hline Level $3 u_{00 k}$ & $16.92(.00)^{* * *}$ & $17.33(.00)^{* *}$ & $17.48(.00)^{* *}$ & $11.00(.00)^{* *}$ \\
\hline
\end{tabular}

*P<.05. $* P<.01$

3 showed more reinforcements to antisocial talk for adolescents in the mixed condition.

\section{DISCUSSION}

Interest in this issue is more than academic. During adolescence and young adulthood, delinquent and antisocial activities are often perpetuated in the presence of peers (Cairns \& Cairns, 1995). Efforts to prevent the establishment of antisocial relationships and to intervene in those that already formed are likely to emphasize the identification of group moderators. In sum, we found that there were some differences between experimental groups in regards to antisocial talk and its reinforcement: the adolescents from mixed groups spoke less about antisocial topics than delinquent adolescents from pure groups. There were no group differences for normative talk but some differences for reinforcements to normative talk. In comparison to delinquent adolescents from pure delinquent groups, adolescents from mixed and pure normative groups reinforced each other more for discussing normative topics. This result supports the view that normative adolescents reinforce normative talk more and thus may create more of a normative training process. Another consistent predictor of antisocial talk (or decreases in normative talk) was topic: the more the topic was antisocial, the more there was antisocial talk and the less there was normative talk for all three experimental groups. Time showed some effects on antisocial talk for all groups with a peak of antisocial talk and reinforcements at time 2. Specifically, the numbers of group sessions moderated some relationships between experimental groups and talk: time 2 showed less reinforcement to normative talk for adolescents in mixed groups whereas time 3 showed more antisocial talk and reinforcements for these adolescents in mixed groups compared to delinquent adolescents from pure delinquent groups. Time 3 was also associated with more reinforcement to normative talk for nondelinquent adolescents in pure normative groups.

The present research revealed a number of interesting findings. First, there was some deviant talk present in all three experimental conditions underlining the "normative" nature of some deviant talk. Second, there were significant group level differences in normative and deviant talk indicating that having more deviant peers in a group increases the amount of deviant talk. These results are consistent with others studies indicating that the norms inside the group predict behaviors within the group and are based on the characteristics of group members (Henry et al., 2000).

Second, as predicted, adolescents in the mixed condition demonstrated more normative talk and less antisocial talk when compared to adolescents from the pure delinquent groups. It is also important to note that youth in the mixed group exhibited less antisocial talk than youth in the pure delinquent group, but we were not able to directly examine the effect of having youth with a range of delinquent 
behaviors on normative adolescents in this context (and possible iatrogenic effects). Discrepancy between adolescents may permit a sociocognitive conflict (Doise \& Mugny, 1981) and drive delinquent adolescents to higher behavioral and cognitive levels (or possibly entice normative adolescents to be more deviant). As hypothesized, there was more antisocial talk and reinforcements inside pure delinquent groups. These effects can be viewed as support for the importance of the deviancy training process and help to explain the iatrogenic effects in a real environment, such as studies reporting increases in deviancy within schools for delinquents (Lee \& Thompson, 2009; Leve $\&$ Chamberlain, 2005; Shapiro et al., 2010). In regard to nondelinquent adolescents from the pure normative condition, it was surprising to observe no significant differences between these adolescents and those from the pure delinquent condition, with the exception of reinforcements to normative talk during the last collective session. This outcome was not consistent with our hypothesis that pure normative groups would demonstrate the least amount of deviant talk and more normative talk than delinquent adolescents from pure groups. Qualitatively, from watching videotapes, it appeared that these nondelinquent adolescents goofed off more during the sessions, making jokes or telling inventive stories about the antisocial contents of discussions. Thus, their behavior was coded as deviant even though their deviance as appeared to be less serious than the deviance in the delinquent adolescents from pure delinquent groups. Adolescence is a period of experimentation (White, 1989), so clearly future research would benefit by focusing on more fine-grained coding systems that distinguish between "goofing off" and discussion of more serious delinquent acts. Indeed, the coding system used in the current study used a very liberal criterion for counting behaviors as antisocial. For example, singing, dancing, or eating something without permission were deemed as inappropriate behaviors and coded as antisocial; however, these behaviors are not illegal or particularly deviant in this culture. In future research, these kinds of behaviors could be coded as "minor deviant behaviors" as opposed to "severe deviant behaviors" (e.g., discussing the benefits of dealing drugs or demonstrating verbal violence against one peer of the group). We selected the Deviant Topic Codebook for coding deviant talks, as it has been widely used in the past (Dishion et al., 1996; Dishion et al., 2001; Granic \& Dishion, 2003; Piehler \& Dishion, 2007). However, these observations point to the need for more fine-grained coding systems to improve on this commonly used coding system. Moreover, it requires also having enough vari- ance within behaviors, especially for severe behaviors in all groups. In this study, youths from pure normative and mixed conditions showed little variability in more severe types of deviant talk.

Although age was used in this study as a covariate, it is worth noting that the age of the adolescents did not predict normative or antisocial talk. This result is not consistent with other studies (Berndt, 1979; Brown, 1990) that found that peer influence has the greatest impact during early and mid-adolescence. However, the age range sampled in this study was not wide enough to distinguish early from mid and late adolescence or to address the result that early adolescents are the most vulnerable to deviancy training process with older adolescents (Dodge et al., 2006; Greenwood, 2006; Mahoney \& Stattin, 2000; Vitaro et al., 1997).

This study also emphasized that the topic of talk was very important and having antisocial content as a topic within interactions increased antisocial talk and attitudes and decreased normative talk. These results could explain why interventions based only on talking about problem behavior (e.g., those focused on risky sexual behaviors (Moeberg \& Piper, 1998) or consumption of drugs (Valente et al., 2007)) showed iatrogenic effects with an increase of undesirable behaviors. Researchers and social workers may wish to put more focus on positive topics instead of letting adolescents talk about their crimes, as the latter appears to be associated with an increase of deviant talk within groups.

Time was also important: the second session was associated with more antisocial talk for all experimental conditions, in comparison to the first session with more normative talk. This result was surprising as we hypothesized a stable increase at time 2 and time 3 or an increase at time 3 only, as more familiarity between adolescents would lead to the development of more deviant talk. One possible explanation could be the adolescents become familiar at time 2 and showed a habituation to the task at time 3 . Another reason could be an effect of the content of stories used at time 2: the antisocial topic was about the financial benefits from dealing drugs without hurting someone, while topics for time 1 and 3 included harming someone. These kinds of stories appeared effective at eliciting deviant talk, as it might have desensitized adolescents from discussing the notion of harming someone and encouraged adolescents to make negative statements about others. However, the type of story and time were confounded in this study and thus we cannot evaluate whether it was the number of sessions or particular story driving these findings. That being said, as stories have been rated by others adolescents to be 
progressively more antisocial, it could be more likely that the effects are based on some aspect of group interactions in the second session rather than story type. Future studies are clearly needed to disentangle this nuanced point.

Finally, several moderator effects emerged in which time moderated the links between experimental conditions and talk. Thus, adolescents in the mixed condition used less reinforcements to normative talk during the second session and more antisocial talk and reinforcements associated during the last collective session, whereas the adolescents from pure normative condition used more reinforcements to normative talk at the third session. Even if the mixed condition seems to be the most promising context for preventing deviancy training, the results across the sessions showed an increase of antisocial talk and reinforcements for these adolescents. It is possible that these adolescents with different profiles and who did not know each other were more comfortable expressing their ideas and spoke about deviant things more after the first session. Accordingly, youth in mixed groups may become more deviant after more time has elapsed. Again, more research on this topic is needed, as this study was relatively novel in examining these particular aspects of the deviancy training process. In particular, convening longer group sessions and perhaps for a longer time may have stimulated greater frequencies and more severe percentages of deviant talk, especially to better evaluate the mixed group.

Finally, one issue that future studies need to consider is the effect of fostering friendships between delinquent and nondelinquent youth in the context of studies or interventions. In this study, youth were only observed and monitored during a group session. This design was similar to the setup of an intervention or other supervised setting (e.g., school, sports), but clearly does not address what occurs between peers when they are unsupervised. Thus, the presence of an adult in the session is both a strength and a weakness and further research is needed examining the interactions when adults are not present.

\section{Limitations and Directions for Future Research}

In this study, the goal was to experimentally manipulate and observe the composition of groups of adolescent youth differing in their histories of delinquent behavior, especially a mixed group of delinquent and normative youth, in deviant talk and behavior in sessions. As these data were crosssectional (but also experimental), more studies are needed to connect these processes to behavior outside the laboratory and without an adult present. Though the current experimental design mimicked the setup of some settings (interventions, school, sports teams), much of deviancy training is likely to happen when adults are not present and thus studies are needed that examine these processes without adults in the room. The study focused also on adolescents within a rather small age range. The extent to which our findings could be generalized to other age groups remains an empirical question. This study was only composed of adolescent boys, thus the results may not generalize to girls and more research is needed examining these processes within girls or within mixed-gender groups. Moreover, as noted above, the differences by time (time 1,2,3) were difficult to interpret, especially because time and the type of stories are confounded. Future studies are also clearly needed to distinguish between time and topic effects on deviant talk between these three experimental conditions.

Our study also has several notable strengths to balance out these limitations. First, we used an innovative experimental design with observational methods. Moreover, to have a similar design to the group sessions often used in residential care services, we conducted multiple sessions to observe the manifestations of antisocial and normative talk among three conditions varying in levels of prior delinquent behavior. Previous studies on group interventions have often focused on one profile: delinquent youths (Lee \& Thompson, 2009; Leve \& Chamberlain, 2005; Shapiro et al., 2010), nondelinquent adolescents (Boxer et al., 2005; Hanish et al., 2005; Kellam et al., 1998; Snyder et al., 2005; Warren et al., 2005) or these two profiles: one group with delinquent youth and one another group with delinquent and nondelinquent youth, but without control group composed of nondelinquent youth (Feldman, 1992; Hudley \& Graham, 1993, 2007; Mager et al., 2005). In this way, although findings from the current study need to be replicated with larger and more diverse samples, they might contribute to the understanding of deviancy training processes by the identification of predictor and moderator effects that could improve in future groupbased interventions. Moreover, this study helps add to our understanding of deviant peer processes when combining delinquent and nondelinquent youth.

\section{REFERENCES}

Ang, R. P., \& Hughes, J. N. (2001). Differential benefits of skills training with antisocial youth based on group composition: A meta-analytic investigation. School Psychology Review, 31, 164 185.

Arnold, C. L. (1992). An introduction to hierarchical linear models. Measurement and Evaluation in Counseling and Development, 25, 58-90. 
Atwood, R. O., \& Osgood, D. W. (1987). Cooperation in group treatment programs for incarcerated adolescents. Journal of Applied Social Psychology, 17, 969-989.

Bayer, P., Pintoff, R., \& Pozen, D. (2004). Building criminal capital behind bars: Peer effects in juvenile corrections (Paper $N^{\circ}$. 864). New Haven: Yale University, Economic Growth Center Discussion.

Bereiter, C. (1963). Some persisting dilemmas in the measurement of change. In C. Harris (Ed.), Problems in measuring change (pp. 3-20). Madison, WI: University of Wisconsin Press.

Berndt, T. (1979). Developmental changes in conformity to peers and parents. Developmental Psychology, 15, 608-616.

Boivin, M., Dodge, K. A., \& Coie, J. D. (1995). Individual-group behavioral similarity and peer status in experimental play groups of boys: The social misfit revisited. Journal of Personality and Social Psychology, 69, 269-279.

Born, M. (2005). En milieu scolaire : de la victimisation à l'agression et inversement. In B. Gaillard (Ed.), Les violences en milieu scolaire et éducatif: connaitre, prévenir, intervenir (pp. 175-183). Rennes: Presses universitaires.

Born, M., Spitz, J., \& Gavray, C. (2000). Student Self-report Survey. Unpublished instrument. Department of psychology of delinquency, Liege, Belgium: University of Liege.

Boxer, P., Guerra, N. G., Huesmann, L. R., \& Morales, J. (2005). Proximal peer-level effects of a small-group selected prevention on aggression in elementary school children: An investigation of the peer contagion hypothesis. Journal of Abnormal Child Psychology, $33,325-338$.

Brechwald, W. A., \& Prinstein, M. J. (2011). Beyond homophily: A decade of advances in understanding peer influence processes. Journal of Research on Adolescence, 21, 166-179.

Brown, B. B. (1990). Peer groups and peer cultures. In S. S. Feldman \& G. R. Elliot (Eds.), At the threshold: The developing adolescent (pp. 171-196). Cambridge, MA: Harvard University Press.

Buehler, R. E., Patterson, G. R., \& Furniss, J. M. (1966). The reinforcement of behavior in institutional settings. Behavior Research and Therapy, 4, 157-167.

Burr, J. A., \& Nesselroade, J. R. (1990). Change measurement. In A. von Eye (Ed.), Principles and structuring change, Vol. 1, (pp. 3-35). Boston: Academic Press.

Cairns, R. B., \& Cairns, B. D. (1995). Social ecology over time and space. In P. Moen, G. H. Elder \& U. K. Luscher (Eds.), Examining lives in context: Perspectives on the ecology of human development (pp. 379-421). Washington, DC: American Psychological Association.

Callan, T., \& Nolan, B. (1991). Concepts of poverty and the poverty line. Journal of Economic Surveys, 5, 243-261.

Chassin, L., Hussong, A., Barrera, M., Molina, B., Trim, R., \& Ritter, J. (2004). Adolescent substance use. In R. Lerner, L. Steinberg (Eds.), Handbook of adolescent psychology (pp. 665-696). 2nd ed. New York: Wiley.

Cho, H., Halfors, D., \& Sanchez, V. (2005). Evaluation of a high school peer group intervention for at risk youth. Journal of Abnormal Child Psychology, 33, 363-374.

Dennis, M., Godley, S. H., Diamond, G., Tims, F. M., Barbor, T., Donaldson, J. (...), \& Funk, R. (2004). The Cannabis Youth Treatment (CYT) study: Main findings from two randomized trials. Journal of Substance Abuse Treatment, 27, 197-213.

Deutsch, M. (1949). Theory of cooperation and competition. Human Relations, 2, 129-152.

Dishion, T. J., Capaldi, D. M., Spracklen, K. M., \& Li, F. (1995). Peer ecology of male adolescent drug use. Development and Psychopathology, 7, 803-824.

Dishion, T. J., Dodge, K. A., \& Lansford, J. E. (2008). Deviant by design: Risks associated with aggregating deviant peers into group prevention and treatment programs. The Prevention Researcher, 15, 8-11.

Dishion, T. J., Eddy, J. M., Haas, E., Li, F., \& Spracklen, K. (1997). Friendships and violent behavior during adolescence. Social Development, 6, 207-223.

Dishion, T. J., McCord, J., \& Poulin, F. (1999). When interventions harm: Peer groups and problem behavior. American Psychologist, 54, 755-764.

Dishion, T. J., Poulin, F., \& Burraston, B. (2001). Peer group dynamics associated with iatrogenic effects in group interventions with highrisk young adolescents. New Directions for Child and Adolescent Development, 91, 79-92.

Dishion, T. J., Spracklen, K. M., Andrews, D. W., \& Patterson, G. R. (1996). Deviancy training in male adolescent friendships. Behavior Therapy, 27, 373-390.

Dishion, T. J., \& Tipsord, J. (2011). Peer contagion in adolescent and child social and emotional development. Annual Review of Psychology, 62, 189-214.

Dodge, A., Dishion, T. J., \& Lansford, J. E. (2006). Deviant peer influences in programs for youth. New York: The Guilford press.

Doise, W., \& Mugny, G. (1981). Le développement social de l'intelligence. Paris: InterÉditions.

Eisenberg, N., Smith, C. L., Sadovsky, A., \& Spinrad, T. L. (2004). Effortful control: Relations with emotion regulation, adjustment, and socialization in childhood. In R. F. Baumeister (Ed.), Handbook of self regulation: Research, theory, and applications (pp. 259-282). New York: Guilford Press.

Ellis, L. K., Rothbart, M. K., \& Posner, M. I. (2004). Individual differences in executive attention predict self-regulation and adolescent psychosocial behaviors. Annals of the NY Acadademy of Sciences, $1-21,331-340$

Englund, M., Levy, A., Hyson, D., \& Sroufe, L. (2000). Adolescent social competence: Effectiveness in a group setting. Child Development, 71, 1049-1060.

Erickson, K. G., Crosnoe, R., \& Dornbusch, S. M. A. (2000). Social process model of adolescent deviance: Combining social control and differential association perspectives. Journal of Youth and Adolescence, 16, 395-425.

Feldman, R. A. (1992). The St. Louis Experiment: Effective treatment of antisocial youths in prosocial peer groups. In J. McCord, R. E. Tremblay (Eds.), Preventing antisocial behavior: Interventions from birth to adolescence (pp. 233-252). New York: Guilford Press.

Fergusson, D. M., Wanner, B., Vitaro, F., Horwood, L. J., \& SwainCampbell, N. (2003). Deviant peer affiliation and depression: Confounding or causal? Journal of Abnormal Child Psychology, 31, 605-618.

Fontaine, R. G., Burks, V. S., \& Dodge, K. A. (2002). Response decision processes and externalizing behavior problems in adolescents. Development and Psychopathology, 14, 107-122.

Fontaine, N., \& Vitaro, F. (2006). L'utilisation de pairs prosociaux dans les programmes d'intervention auprès de jeunes en difficulté d'adaptation. Revue de Psychoéducation, 35, 11-42.

Granic, I., \& Dishion, T. J. (2003). Deviant talk in adolescent friendships: A step toward measuring a pathogenic attractor process. Social Development, 12, 314-334.

Granic, I., \& Hollenstein, T. (2003). Dynamic systems methods for models of developmental psychopathology. Development and Psychopathology, 15, 641-669.

Greenwood, P. (2006). Promising solutions in juvenile justice. In A. Dodge, T. J. Dishion, \& J. E. Lansford (Eds.), Deviant peer influences in programs for youth (pp. 278-295). New York: Guilford press. 
Handwerk, M. L., Field, C. E., \& Friman, P. C. (2000). The iatrogenic effects of group interventions: Premature extrapolations. Journal of Behavioral Education, 10, 223-238.

Hanish, L. D., Martin, C. L., Fabes, R. A., Leonard, S., \& Herzog, M. (2005). Exposure to externalizing peers in early childhood: Homophily and peer contagion processes. Journal of Abnormal Child Psychology, 33, 267-281.

Hawkins, J. D., Jenson, J. M., Catalano, R. F., \& Wells, E. A. (1991). Effects of a skills training intervention with juvenile delinquents. Research on Social Work Practice, 1, 107-121.

Henry, D., Guerra, N., Huesmann, L. R., Tolan, P., Van Acker, R., \& Eron, L. D. (2000). Normative influences on aggression in urban elementary school classrooms. American Journal of Community Psychology, 28, 59-81.

Hubbard, J. A., Dodge, K. A., Cillessen, A. H. N., Coie, J. D., \& Schwartz, D. (2001). The dyadic nature of social information processing in boys' reactive and proactive aggression. Journal of Personality and Social Psychology, 80, 268-280.

Hudley, C., \& Graham, S. (1993). An attributional intervention to reduce peer directed aggression among African-American boys. Child Development, 64, 124-138.

Hudley, C. Graham, S., \& Taylor, A. (2007). Reducing aggressive behavior and increasing motivation in school. Educational Psychologist, 47, 251-260.

Jonkmann, K., Trautwein, U., \& Lüdtke, O. (2009). Social dominance in adolescence: The moderating role of the classroom context and behavioral heterogeneity. Child Development, 80, 338-355.

Kashy, D. A., Donnellan, M. B., Burt, S. A., \& McGue, M. (2008). Growth curve models for indistinguishable dyads using multilevel modeling and structural equation modeling: The case of adolescent twin's conflict with their mothers. Developmental Psychology, 44, 316-329.

Kellam, S., Ling, X., Merisca, R., Brown, H., \& Ialongo, N. (1998). The effect of the level of aggression in the first grade classroom on the course and malleability of aggressive behavior into the middle school. Development and Psychopathology, 10, 165-185.

Kenny, D. A., Bolger, N., \& Kashy, D. A. (2002). Traditional methods for estimating multilevel models. In D. S. Moskowitz \& S. L. Hershberger (Eds.), Modeling intraindividual variability with repeated measures data: Methods and applications (pp. 1-24). Mahwah, NJ: Lawrence Erlbaum Associates.

Larsen, H., Engels, R. C., Granic, I., \& Overbeek, G. J. (2009). An experimental study on imitation of alcohol consumption in samesex dyads. Alcohol and Alcoholism, 44, 250-255.

Larsen, H., Engels, R. C., Souren, P. M., Granic, I., \& Overbeek, G. J. (2010). Peer influence in a micro-perspective: Imitation of alcoholic and non-alcoholic beverages. Addictive Behaviors, 35, 4952.

Larson, R. W., \& Brown, J. R. (2007). Emotional development in adolescence: What can be learned from a high school theatre program? Child Development, 78, 1083-1099.

Le Blanc, M, Dionne, J., Proulx, J., Grégoire, J., \& Trudeau Le Blanc, P. (1998). Intervenir autrement: Un modèle différentiel pour les adolescents en difficulté. Québec: Les presses de l'Université de Montréal.

Lee, B. R., \& Thompson, R. (2009). Examining externalizing behavior: Behavior trajectories of youth in group homes: Is there evidence for peer contagion? Journal of Abnormal Child Psychology, 37, 3144.

Leve, L. D., \& Chamberlain, P. (2005). Association with delinquent peers: Intervention effects for youth in the juvenile justice system. Journal of Abnormal Child Psychology, 33, 339-347.

Lipsey, M. (2006). The effects of community-based group treatment for delinquency: A meta-analytic search for cross-study generaliza- tions. In K. A. Dodge, T. J. Dishion \& J. E. Lansford (Eds.), Deviant peer influences in programs for youth: Problems and solutions (pp. 162-184). New York: Guilford.

Lipsey, M. W., Wilson, D. B., \& Cothern, L. (2000). Effective intervention for serious offenders. Washington DC: Department of justice, Office of Juvenile Justice and Delinquency Prevention.

McMahon, R. J., \& Wells, K. C. (1998). Conduct problems. In E. J. Mash \& R. A. Barkley (Eds.), Treatment of childhood disorders (pp. 111-207). 2nd ed. New York: Guilford.

Mahoney JL, \& Stattin H. (2000). Leisure activities and adolescent antisocial behavior: The role of structure and social context. Journal of Adolescence, 23, 113-127.

Mahoney, J. L., Stattin, H., Lord, H. \& (2004). Participation in unstructured youth recreation centers and the development of antisocial behavior: Selection processes and the moderating role of deviant peers. International Journal of Behavioral Development, 28 , 553-560.

Mager, W., Milich, R., Harris, M. J., \& Howard, A. (2005). Intervention groups for adolescents with conduct problems: Is aggregation harmful or helpful? Journal of Abnormal Child Psychology, 33, 349-362.

Mathys, C., \& Born, M. (2009). Intervention in juvenile delinquency: Danger of iatrogenic effects? Children and Youth Services Review, $31,1217-1221$.

Moberg, D. P., \& Piper, D. L. (1998). The healthy for life project: Sexual risk behavior outcomes. AIDS Education and Prevention $10,128-148$

Nangle, D. W., Erdley, C. E., Carpenter, E. M., \& Newman, J. E. (2002). Social skills training as a treatment for aggressive behavior among children and adolescents: A developmental-clinical integration. Aggression and Violent Behavior, 7, 169-199.

Nas, C, Brugman, D., \& Koops, W. (2005). Effects of a multicomponent peer intervention program for juvenile delinquents on moral judgment cognitive distortions, social skills and recidivism. Psychology, Crime, Law, 11, 421-434.

Palinkas, L. A., Atkins, C. J., Miller, C., \& Ferreira, D. (1996). Social skills training for drug prevention in high-risk female adolescents. Preventive Medicine, 25, 692-701.

Patterson, G. R., Dishion, T. J., \& Yoerger, K. (2000). Adolescent growth in new forms of problem behavior: Macro and micro-peer dynamics. Prevention Science, 1, 3-13.

Pearson, F. S., Lipton, D. S., Cleland, C. M., \& Yee, D. S. (2002). The effects of behavioral/cognitive-behavioral programs on recidivism. Crime \& Delinquency, 48, 476-496.

Peterson, J., Piehler, T. F., \& Dishion, T. J. (2006). Topic code v. 3.0. manual for the peer interaction task. Unpublished instrument. Child and Family Center, University of Oregon, Oregon, USA.

Piehler, T. F., \& Dishion, T. J. (2007). Interpersonal dynamics within adolescent friendships: Dyadic mutuality, deviant talk, and the development of antisocial behavior. Child Development, 78, 16111624.

Plybon, L. E., \& Kliewer, W. (2001). Neighborhood types and externalizing behavior in urban school-age children: Tests of direct, mediated, and moderated effects. Journal of Child and Family Studies, 10, 419-437.

Poulin, F., Dishion, T. J., \& Burraston, B. (2001). 3-Year iatrogenic effects associated with aggregating high-risk adolescents in cognitivebehavioral preventive interventions. Applied Developmental Science, 5, 214-224.

Raudenbush, S. W., \& Bryk, A. S. (2002). Hierarchical linear models (Second Edition). Thousand Oaks: Sage Publications.

Shapiro, C. J., Smith, B. H., Malone, P. S., \& Collaro, A. L. (2010). Natural experiment in deviant peer exposure and youth recidivism. Journal of Clinical Child and Adolescent Psychology, 39, 242-251. 
Short, J. F., \& Strodtbeck, F. L. (1965). Group Process and gang delinquency. Chicago: The University of Chicago Press.

Simons-Morton, B., Lerner, N., \& Singer, J. (2005). The observed effects of teenage passengers on the risky driving behaviour of teenage drivers. Accident analysis and prevention, 37, 973-982.

Singer, J. D., \& Willett, J. B. (2003). Applied longitudinal data analysis: Modeling change and event occurrence. New York, NY: Oxford University Press.

Snijders, T. A. B. (2003). Multilevel analysis. In M. Lewis-Beck, A. E. Bryman, \& T. F. Liao (Eds.), The SAGE encyclopedia of social science research methods, Vol. II (pp. 673-677). New York: Sage.

Snyder, J. Schrepferman, L., Oeser, J., Patterson, G. R., Stoolmiller, M., Johnson, K., \& Snyder, A. (2005). Deviancy training and association with deviant peers in young children: Occurrence and contribution to early-onset conduct problems. Development \& Psychopathology, 17, 397-413.

Stormshak, E. A., Bierman, K. L., Bruschi, C., Dodge, K. A., \& Coie, J. D. (1999). The relation between behavior problems and peer preference in different classroom contexts. Child Development, 70, $169-182$.

Steinberg, L., \& Monahan, K. (2007). Age differences in resistance to peer influence. Developmental Psychology, 43, 1531-1543.

Thornberry, T. P., \& Krohn, M. D. (1997). Peers, drug use, and delinquency. In D. Stoff, J. Breiling, \& J. Maser (Eds.), Handbook of antisocial behavior (pp. 218-233). New York: Wiley.

Tremblay, R. E., Masse, L. C., Vitaro, F., \& Dobkin, P. L. (1995). The impact of friend's deviant behavior on early onset of delinquency: Longitudinal data from 6 to 13 years of age. Development and Psychopathology, 7, 649-667.

Valente, T. W., Ritt-Olsen, A., Stacy, A., Unger, J. B., \& Okamoto, J., Sussman, S. (2007). Peer acceleration: Effects of a social network tailored substance abuse prevention program among high-risk adolescents. Addiction, 102, 1804-1815.
Vitaro, F., Brendgen, M., \& Tremblay, R. E. (2001). Preventive intervention: Assessing its effects on the trajectories of delinquency and testing for mediational processes. Applied Developmental Science, 4, 201-213.

Vitaro, F., Tremblay, R. E., Kerr, M., Pagani, L., \& Bukowski, W. M. (1997). Disruptiveness, friends' characteristics, and delinquency in early adolescence: A test of two competing models of development. Child Development, 68, 676-689.

Vorrath, H., \& Bendtro, T. K. (1974). Positive peer culture. Chicago: Adline.

Warren, K., Schoppelrey, S., Moberg, D. P., \& McDonald, M. (2005). A model of contagion through competition and aggressive behavior of elementary students. Journal of Abnormal Child Psychology, 33, 283-292.

Weiss, B., Caron, A., Ball, S., Tapp, J., Johnson, M., \& Weisz, J. R. (2005). Iatrogenic effects of group treatment for antisocial youth. Journal of Consulting and Clinical Psychology, 73, 10361044.

Wheeler, S. (1961). Socialization in correctional communities. American Sociological Review, 26, 697-712.

White, J. L. (1989). The troubled adolescent. New York: Pergamon.

Willett, J. B. (1990). Measuring change: The difference score and beyond. In H. J. Walberg \& G. D. Haertel (Eds.), International encyclopedia of educational evaluation (pp. 632-637). Oxford, England: Pergamon Press.

Young, R. A., Marshall, S. K., Domene, J., Graham, M., Logan, C., \& Zaidman-Zait, A. (2008). Transition to adulthood as a family project: Governance transfer, career promotion and relationship. Journal of Counseling Psychology, 55, 297-307.

Wright, J. C., Giammarino, M., \& Para, H. W. (1986). Social status in small groups: Individual group similarity and the social 'misfit'. Journal of Personality and Social Psychology, 50, 523536. 